\title{
A Inovação no Design de Animação para Stop Motion: as Experiências da Animaking
}

The Innovation in Animation Design for Stop Motion: The Experiments of Animaking

MACEDO, Thales Eduardo; Graduado; Universidade Federal de Santa Catarina - Animaking thales@animaking.com.br

CONTI, Paolo; Mestrando; Universidade Federal de Santa Catarina - Animaking paolo@animaking.com.br

OURIVES, Eliete Auxiliadora Assunção; Pós-doutora; Universidade Federal de Santa Catarina elieteourives@gmail.com

FIGUEIREDO, Luiz Fernando Gonçalves de; Pós-doutor; Universidade Federal de Santa Catarina Iffigueiredo2009@gmail.com

CESTARI, Glauba Alves do Vale; Doutoranda; Universidade Federal de Santa Catarina glauba.cestari@ifma.edu.br FERRARI, Aldo Sigolo; Graduado; Universidade Federal de Santa Catarina aldoferrari@uol.com.br

\section{Resumo}

Esta pesquisa tomou como estudo de caso a empresa Animaking, com foco em dois trabalhos: Minhocas, o filme (2013) - o primeiro longa-metragem de animação stop motion do Brasil - e Suspicious Reflection (2018) - curta-metragem desenvolvido como teaser e laboratório da técnica de produção do próximo filme da franquia. Os dados foram coletados nas fontes da empresa e correlacionados a um suporte documental com base em livros e publicações. O objetivo é análise comparativa da evolução técnica e processual das duas produções registrando transformações e evoluções trazidas pela inserção de meios digitais à técnica artesanal de animação stop motion.

Palavras Chave: Stop Motion; prototipagem; processos digitais.

\begin{abstract}
This research took as case the company Animaking, focusing on two works: Worms, the film (2013) - the first feature stop motion animation of Brazil - and Suspicious Reflection (2018) - short film developed as a teaser and a testing environment of the next film's production technique. The data were collected in the sources of the company and correlated to a documentary support based on books and publications. The objective is a comparative analysis of the technical and procedural evolution of the two productions, registering transformations and evolutions brought about by the insertion of digital media to the artisan technique of stop motion animation.
\end{abstract}

Keywords: Stop Motion; prototyping; digital processes. 


\title{
1 Introdução
}

O cinema de animação não se constrói sobre improvisos, mas precisa ser adaptável conforme a situação de necessidade sobre uma demanda de pressão e rápida decisão. Segundo Mazza (2009: 158) "Os filmes não acontecem somente, eles são trabalhados. Cada elemento é planejado e projetado." Por isso na produção de um filme de animação é perceptível a necessidade de uma longa pré-produção na qual realiza-se a experimentação de métodos, técnicas e ferramentas necessárias para o desenvolvimento de ideias, soluções e novos recursos de design.

\begin{abstract}
"O design de animação, como várias outras formas de design, deve se relacionar com a produção e selecionar a larga variedade de critérios que interferem no propósito do filme, os métodos de manufatura, seu uso e distribuição. $O$ processo inteiro de produção de um filme de animação, mesmo que seja modesto, tem a necessidade do design. A metodologia adotada, o desenvolvimento do projeto, a tecnologia utilizada em produção, o tipo e montante de recursos disponíveis, inclusive de pessoal, a equipe de produção, o nível de habilidades disponíveis para os mesmos e os paradigmas de produção são redirecionados pelas decisões de design." (Mazza, 2009: 165).
\end{abstract}

No caso da produtora de animação Animaking essas decisões de design e a experimentação de método e técnica já se iniciam sobre todo o aprendizado adquirido na realização do primeiro longa-metragem de stop motion do Brasil - Minhocas, o Filme. O longa infantil de 82 minutos finalizado em 2013 narra a história de Júnior, uma minhoca que é acidentalmente escavada para fora da terra e precisa voltar para casa. Porém, antes, ele precisa impedir os planos de dominação de um terrível tatu-bola.

A empresa Animaking, com sede em Florianópolis, é uma produtora de animação com foco na criação de conteúdos inovadores para área do entretenimento. Dentro dessa visão, a Animaking desenvolveu metodologias, processos e equipamentos voltados para o mercado cinematográfico e que a projetaram como uma referência na produção de animação na técnica stop motion.

O termo stop motion refere-se "a técnica de criar a ilusão de movimento ou desempenho por meio da gravação, quadro a quadro, da manipulação de um objeto sólido, boneco ou imagem de recorte em um cenário físico espacial" (Purves, 2011, p. 06). Desde a sua popularização, na década de 1990, a animação em stop motion encanta inúmeros espectadores através da sua "mágica": "Stop motion é [...] exatamente assim. Nós sabemos que é um truque, e gostamos disso." (Purves, 2008: 4, tradução nossa).

Para realização desse truque onde a substituição de objetos a cada frame sugere o movimento, o filme Minhocas (2013) utilizou, entre outros recursos, uma impressora 3D na sua produção. O processo serviu para fazer as bocas e expressões dos personagens, possibilitando a sincronia entre as falas e os movimentos labiais. Segundo as informações do relatório do Anima Mundi (2014) o filme Minhocas teve cinco anos de produção, cerca de 70 artistas envolvidos em todo o projeto e foram produzidas mais de 1400 bocas para os personagens.

Nesse momento onde a produtora conduz a pré-produção do seu segundo longametragem, o primeiro longa traz algumas confirmações técnicas a serem mantidas e algumas indicações de possíveis novos caminhos. Dentro das inovações a serem experimentadas e experienciadas, as que se destacam são: 
- O projeto e modelagem digital em software 3D para a produção de peças e moldes em prototipagem rápida;

- E o uso de bocas de troca flexíveis com articulações para possibilitar pequenos e médios movimentos diminuindo assim o número total de bocas físicas necessárias;

\section{Desenvolvimento}

$\mathrm{Na}$ produção do primeiro filme após desenhos e estudos 2D os personagens foram esculpidos de forma artesanal, escaneados tridimensionalmente e as variações de bocas e expressões foram criadas em software 3D.

Figura 1 - Fluxo de processo de criação de personagem no filme Minhocas (2013).

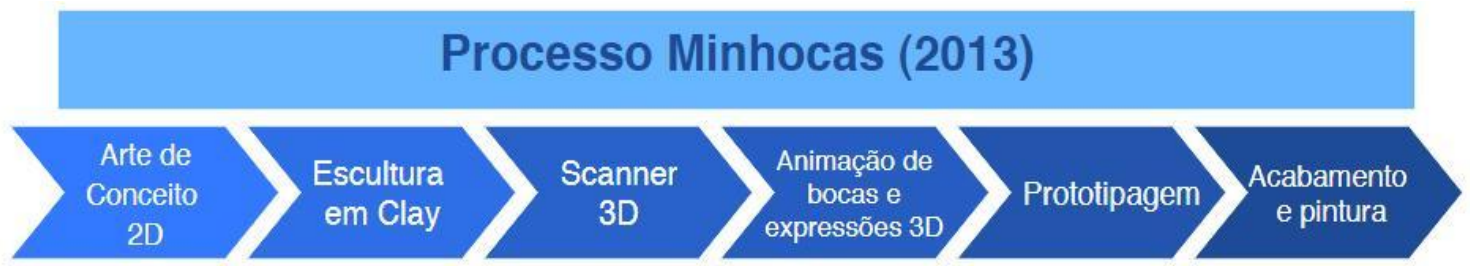

Fonte: o autor

Figura 2 - Processo de construção do personagem no filme Minhocas (2013).

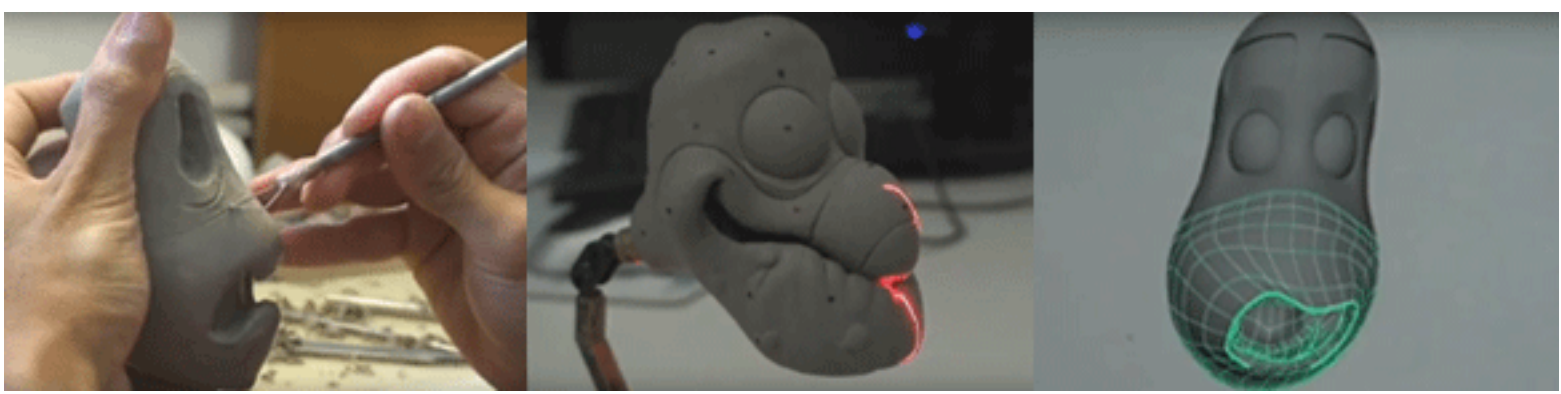

Fonte: o autor

Ken Prieb relata processo muito semelhante na produção americana do longa-metragem em stop motion Coraline (2009):

"O processo começou com os meios tradicionais antes de ser digital. As alterações da expressão facial e a sincronização dos lábios foram projetadas e animadas em 2D e, em seguida, as poses-chaves foram esculpidas como maquetes de clay e digitalizadas no computador. [...] As seqüências inteiras foram animadas em CG. Cada quadro individual da animação foi exportado como um arquivo STL (estereolitografia) e impresso em uma impressora Objet 3D. [...] Uma vez impressa, cada peça modelada precisa ter qualquer material de suporte extra removido, lavado, esfregado, lixado e enviado ao departamento de fabricação para pintura. Cada personagem poderia ter até 15.000 rostos e até 250.000 expressões faciais disponíveis, tudo em registro perfeito um para o outro. A variedade de expressões foi criada dividindo o rosto em metades superior e inferior, de modo que os movimentos da boca e a sincronização dos lábios poderiam ser combinados com movimentos de sobrancelha em muitas combinações diferentes." (Priebe, 2010 p. 141) 
Na produção de Coraline, Priebe relata que "a quantidade de escultura e trabalho de modelagem produzida para o filme foi estimada para ser o equivalente a quase 30 anos de escultura tradicional; [a] prototipagem rápida permitiu que este montante fosse produzido em cerca de 18 meses." (Priebe, 2010. p. 142).

O filme Minhocas passou por esse mesmo desafio só sendo viável a produção de um volume tão grande de bocas com dimensões e encaixes milimetricamente padronizados graças a tecnologia de prototipagem rápida.

Figura 3 - Exemplo do volume de bocas criadas para o filme Minhocas (2013)

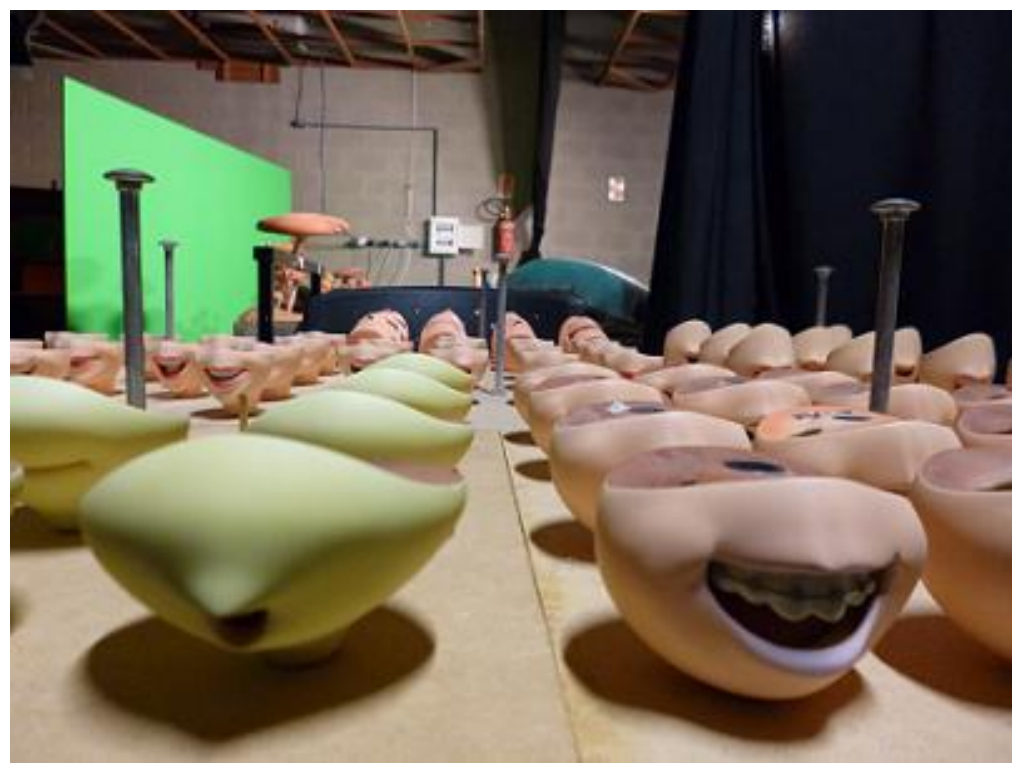

Fonte: Animaking

O termo prototipagem rápida (do inglês: rapid prototyping) refere-se normalmente aos métodos de produção de protótipos por sistemas aditivos (Buswell et al., 2007). Sistema aditivo consiste em sobrepor camadas de material sucessivamente, até que o objeto tridimensional seja formado (Volpato, 2007). Para isso um software cria fatias horizontais do modelo digital, que são impressas, solidificadas ou cortadas, e coladas umas sobre as outras. Isto significa que assim como grande parte de outros objetos prototipados as bocas dos personagens em questão são rígidas não apresentando possibilidade de deformação ou flexibilidade, sendo animadas apenas pela substituição de peças. Para os elementos que precisavam ser flexíveis, como os corpos das minhocas, era necessário a confecção de moldes a partir da escultura feita em Clay ${ }^{1}$.

"Se o puppet (boneco de stop motion) deve ter o corpo coberto de espuma látex ou de silicone, você precisará primeiro esculpir seu modelo, fazer um molde para então despejar esses materiais no molde. [...] A regra geral é: se você está moldando uma peça dura, você precisará de um molde macio (como silicone) e se você estiver fazendo uma peça macia, você precisará de um molde duro (gesso, resina ou fibra de vidro). [...] É melhor usar um clay muito firme na sua escultura, pois os detalhes e as linhas finas devem se manter durante o processo de formação de espuma ou moldagem." (Shaw, 2012 p. 71)

1 Clay é uma massa de modelar a base de óleo que não endurece e pode ser reaproveitada muitas vezes. 
Mais de 100 bonecos articulados foram confeccionados para os 40 personagens do filme Minhocas. O processo usado para a criação de moldes rígidos se assemelha ao descrito por Priebe:

\begin{abstract}
"O objeto esculpido é cercado completamente por uma cama de um tipo diferente de argila [...] geralmente uma não baseada em enxofre é ideal para o processo de fabricação de moldes. A cama de argila é continuamente alisada e enrolada em torno da escultura com uma ferramenta semelhante a uma paleta para que fique hermético e se alinhe exatamente através do ponto médio em uma linha perfeitamente reta em torno de seu perímetro. $\mathrm{O}$ ponto onde a cama de argila toca a escultura é onde a emenda será localizada quando as duas metades do molde forem juntas e separadas. Em muitos casos, este é o meio exato da escultura, mas dependendo do design do que você está moldando, é útil encontrar um ponto onde a emenda não será muito visível para a câmera. Na cama de argila, os pontos de registro chamados chaves são criados usando qualquer outro objeto rígido redondo ou quadrado, o que ajudará ambas as metades do eventual molde a se encaixarem [...]. É melhor planejar com antecedência como inserir o silicone dentro do molde. É possível apenas despejá-lo nos moldes abertos, mas você pode preferir ter um buraco para derramá-lo enquanto o molde é fechado." (Priebe, 2010 p. 109 tradução nossa)
\end{abstract}

Figura 4 - Exemplo de moldes rígidos artesanais
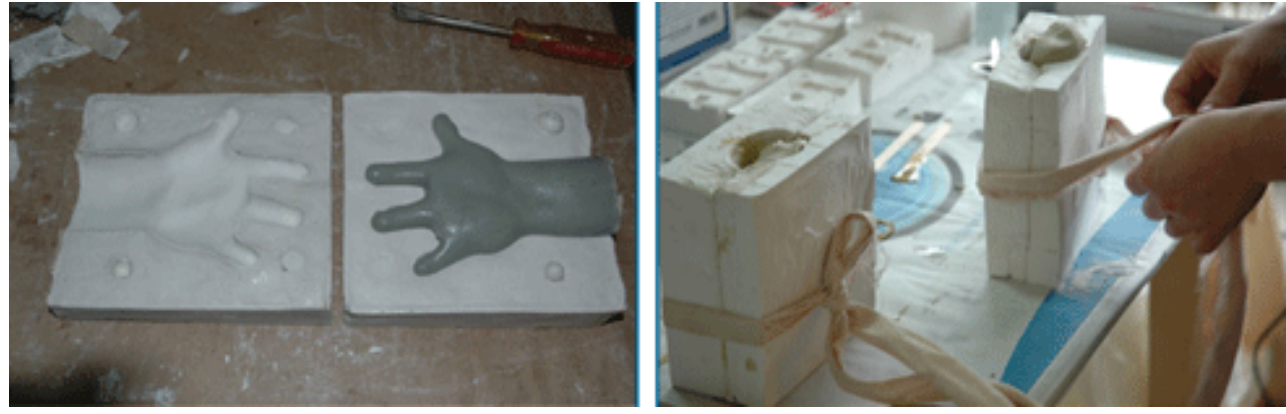

Fonte: Priebe, 2010 p. 111

Segundo registros internos da empresa Animaking, um processo de confecção manual de um molde para um personagem do filme Minhocas poderia facilmente atingir 4 semanas de trabalho de um profissional experiente. As várias etapas deveriam ser perfeitamente concluídas para um resultado adequado, sendo que muitas vezes erros no processo só eram possíveis de correção voltando a etapas iniciais.

A ideia de substituir a escultura em clay e molde artesanal por uma modelagem digital visa a otimização de tempo e entrou em pauta graças à um perceptível avanço na tecnologia digital. $\mathrm{Na}$ época da pré-produção do primeiro filme a opinião dos diretores era que a modelagem 3D poderia limitar os artistas e não entregar um resultado satisfatório em comparação à modelagem artesanal.

Segundo Avgerakis (2004) no início da animação por computação gráfica a única maneira de criar objetos tridimensionais complexos era através da manipulação e combinação de grupos de polígonos. Este método veio a ser conhecido como modelagem poligonal, também chamada como modelagem by poly. A desvantagem deste método é que ele tendia a criar objetos com ângulos proeminentes que deixavam modelos retos e artificiais. Para evitar esse efeito, os polígonos passaram a ser subdivididos em elementos menores até que as bordas tendessem a 
suavizar e desaparecer o que resultava em modelos e arquivos mais pesados em termos de processamento computacional. Com o tempo métodos mais avançados de modelagem digital foram possibilitando arquivos com milhões de polígonos sem um prejuízo perceptível ao desempenho. E a modelagem digital se aliou a uma técnica mais livre e artística conhecida como escultura digital.

Nos primeiros testes de modelagem do personagem para o curta-metragem (2017/2018) percebe-se que a flexibilidade e controle que o digital oferece se reflete no acabamento do personagem que ganha em detalhes. Na escultura em clay há a dificuldade de precisão nos detalhes finos devido ao tamanho real da escultura e sua manipulação já que em média a cabeça de um personagem padrão dentro do projeto Minhocas tem 8 centímetros de altura. Essa dificuldade de escala não existe dentro do ambiente digital 3D.

Figura 5 - Modelagem do personagem “vovô". Exemplo de detalhamento conseguido no ambiente digital (2017)

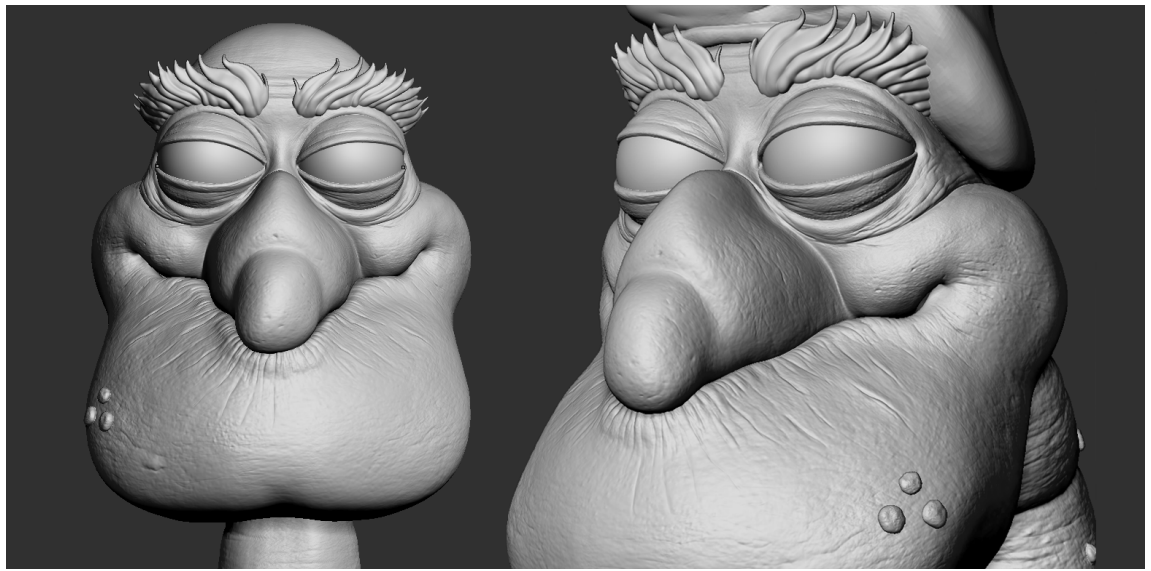

Fonte: Animaking

Figura 6 - Exemplo de detalhamento do primeiro filme

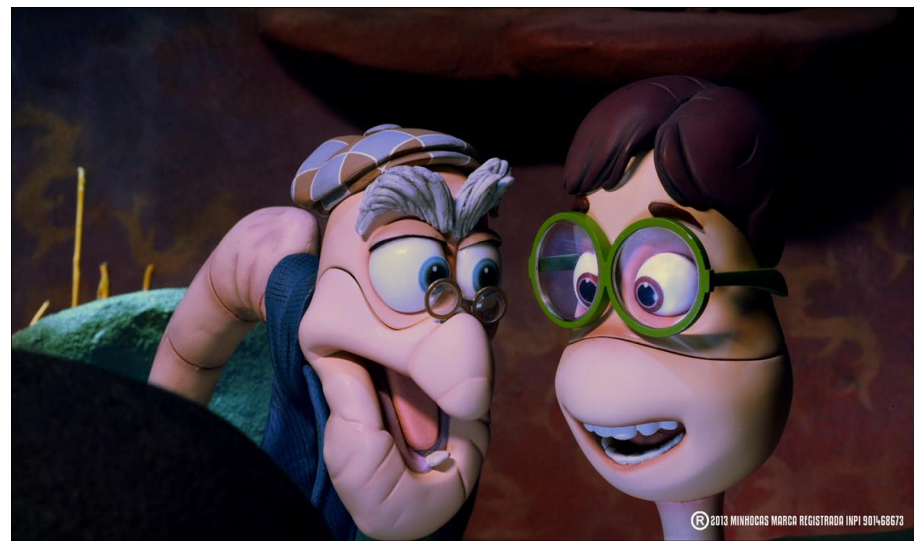

Fonte: Animaking

Porém, "[...] lembre-se que o Stop Motion é uma arte física que ocorre em três dimensões. As coisas devem ser construídas." (Alger (2014) Por mais que o ambiente 3D digital aceitasse os 
detalhes em escalas diminutas os primeiros testes de impressão não corresponderam ao nível de detalhe esperado. Da mesma forma que a tecnologia de modelagem evoluiu do primeiro filme para a pré-produção do segundo; a tecnologia de prototipagem usada anteriormente não tinha resolução para atingir o nível de detalhe atual.

Figura 7 - Comparação do modelo impresso em 3D e o modelo digital. Nota-se a falta de textura na impressão.
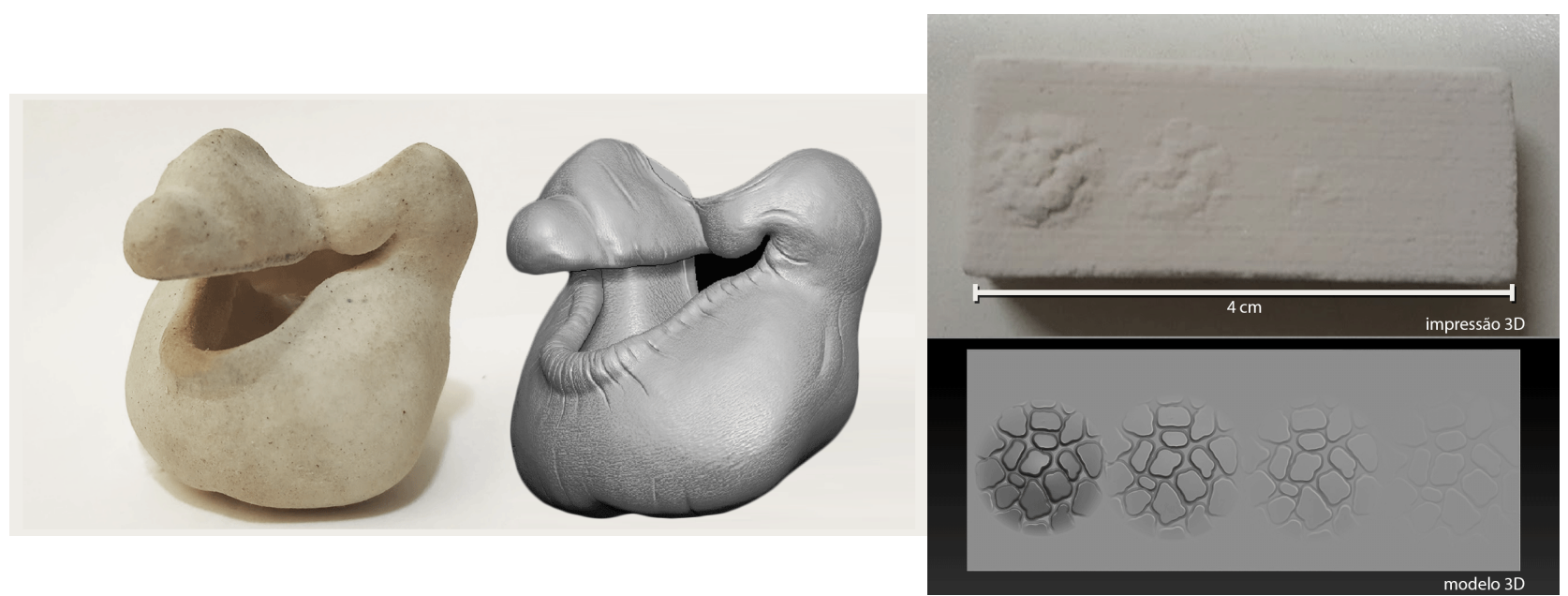

Fonte: Animaking

Como pode ser visto na imagem acima o modelo 3D tem uma escala de detalhes que a prototipagem não conseguia atingir. A impressora utilizada nos testes acima trata-se de um ZPrinter 310 Plus de 2008. Para seguir com os avanços propostos mudou-se a tecnologia de impressão para uma impressora de 2016 a Wanhao D7. Enquanto a impressora de 2008 tinha como medida mínima de impressão $0.102 \mathrm{~mm}$ a Wanhao tem como medida mínima $0.00001 \mathrm{~mm}$, ou seja, 10.000 vezes menor que a impressora anterior.

Figura 8 - Resultado de impressão da Wanhao D7.

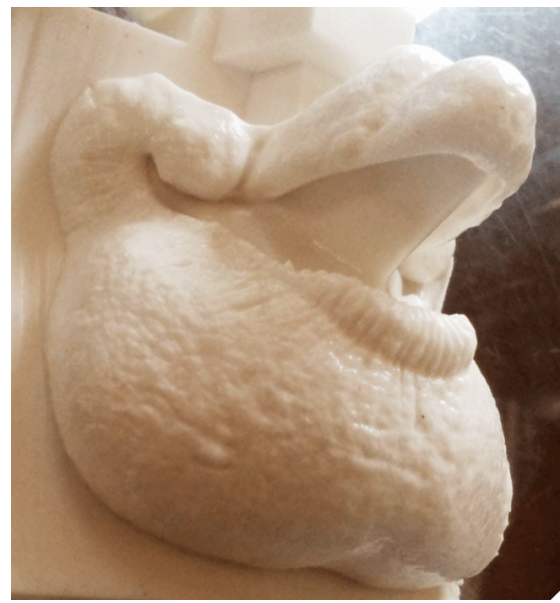

Fonte: Animaking 


\section{Bocas articuladas de troca}

O desafio por trás da técnica de substituição é o grande volume de peças e o trabalho envolvido em prototipar, dar acabamento e pintar cada peça individualmente e ainda mantê-las devidamente padronizadas. Uma alternativa visualizada pela produtora para reduzir o número de bocas de troca foi projetar uma haste que pudesse ser articulada como uma mandíbula fornecendo a cada boca uma amplitude de movimento que na técnica anterior só seria alcançada com o uso em sequência de algumas bocas impressas. Na prática a haste articula a boca até um ponto onde é necessária uma outra boca articulada porém com outro formato gerando uma animação mais dinâmica e flexível com o uso de um menor número de bocas de troca.

Figura 9 - Projeto de articulação da boca.

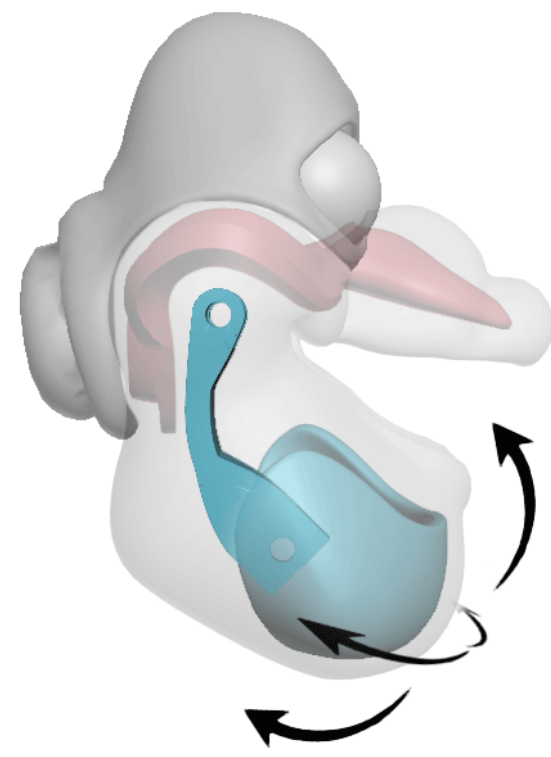

Fonte: Animaking

Esse movimento de articulação só é possível com bocas confeccionadas em material flexível como o silicone e o uso de moldes. A mesma otimização de tempo e qualidade vista na modelagem digital do personagem foi almejada na confecção de moldes, pois ainda que houvesse essa transformação do artesanal para o digital na concepção do personagem os processos subsequentes poderiam continuar de forma artesanal se assim fosse decidido. Ou seja, para transpor o modelo do digital para o físico e gerar um objeto flexível o processo habitual seria imprimir o modelo em uma impressora 3D e fazer o processo já descrito aqui de construção de molde analógico substituindo apenas a primeira etapa de modelagem em clay pela escultura digital.

Ao invés de imprimir a boca diretamente em sua forma positiva a sugestão de investigação técnica e inovação foi projetar toda a estrutura do molde digitalmente e usar recursos computacionais para subtrair o volume da boca modelada de uma peça sólida e imprimir o modelo negativo já escavado em uma parede do molde, fugindo assim das etapas de construção artesanal do molde. 


\section{Artigo Completo}

Figura 10 - Em azul as peças que serão impressas e em vermelho a boca usada para subtrair a estrutura em azul.

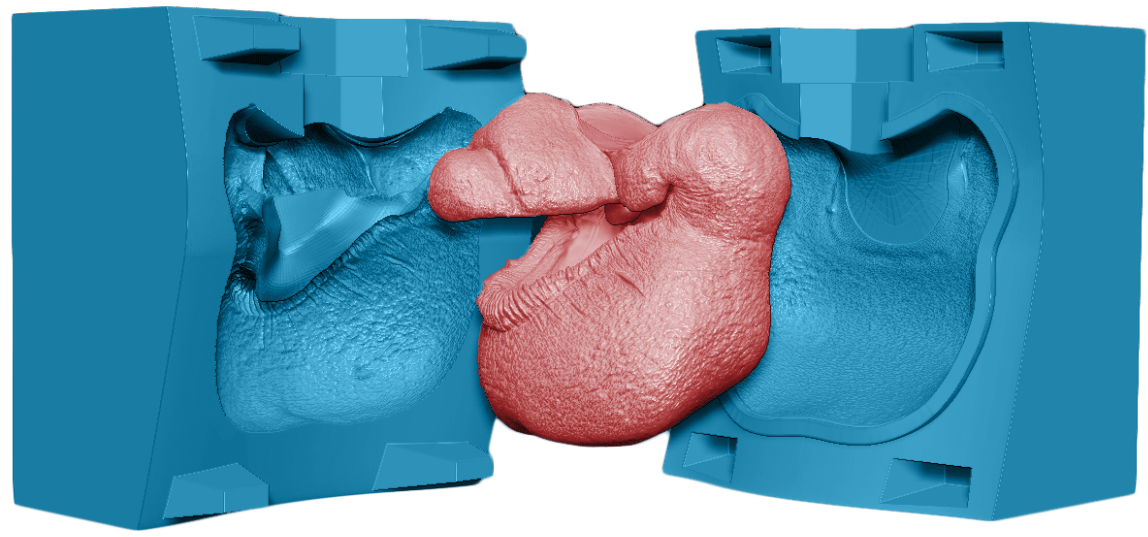

Fonte: Animaking

Figura 11 - Molde impresso em resina fotossensível na impressora Wanhao D7.

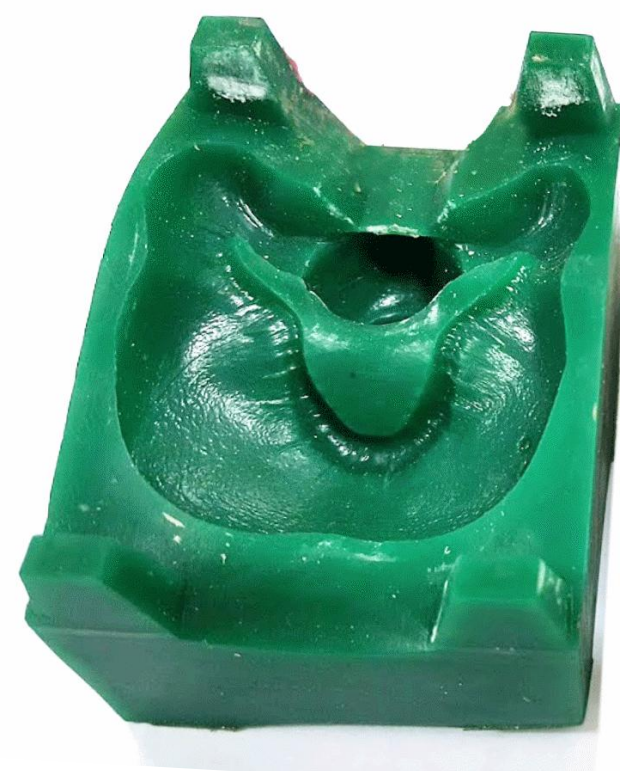

Fonte: Animaking

\section{Conclusão}

O novo método de confecção de moldes testado no curta-metragem em comparação ao método analógico demonstrou possibilitar um projeto mais preciso em termos de acabamento e encaixes devido a alta resolução da prototipadora e a minimização de fatores físicos e manuais na sua construção. Na imagem a seguir fica claro a irregularidade na junção das duas partes do molde analógico ao passo que o molde prototipado consegue uma junção mais regular de suas peças. 
Figura 12- Molde analógico e molde prototipado.

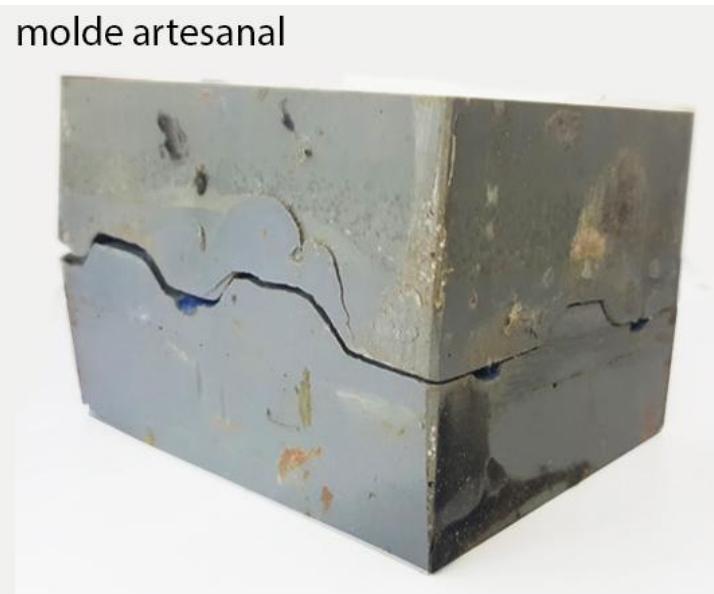

molde prototipado

Fonte: Animaking

Na prática essa precisão se traduz em uma emenda mais limpa no personagem sem grandes excessos de silicone que tenham vazado nessas irregularidades se fazendo necessário um tempo menor de acabamento por personagem. Outra vantagem quanto a emendas é a possibilidade e facilidade de construir no modelo digital a junção dos moldes de forma curva. No molde analógico a superfície de contato das duas partes eram construídas retas e planas pois isso facilitava que durante o processo manual o artesão garantisse a precisão de encaixe. Por consequência disso as emendas criadas eram retas e geralmente dividiam o personagem ao meio. A possibilidade de construir essa junção curva traz a vantagem de posicionar da melhor forma essas emendas visando sempre escondê-las no design do personagem.

Figura 13- Emenda curva escondida na silhueta do personagem.

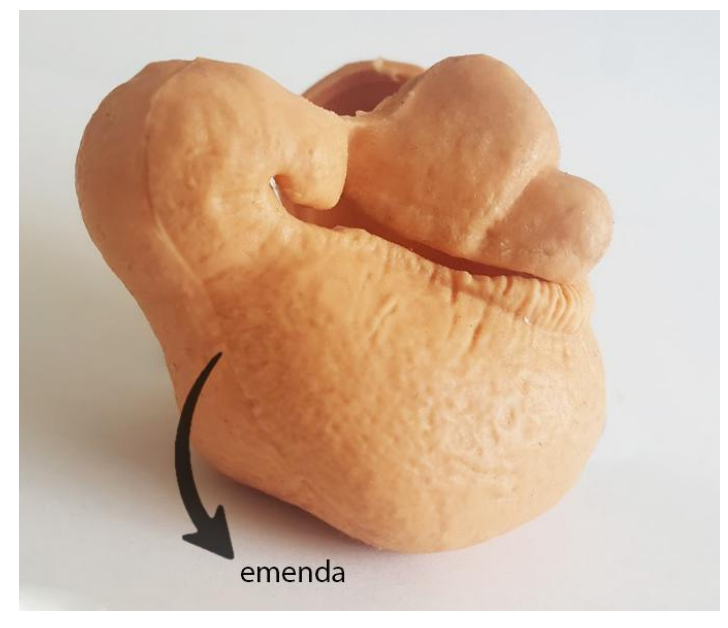

Fonte: Animaking

Nos testes de animação feitos pela Animaking, o uso de bocas articuladas de troca possibilitou ao animador maior liberdade de ação e movimentos mais dinâmicos e fluídos com um número limitado de bocas de troca. Como exemplo disso a seguinte imagem mostra nove quadros 
onde o animador alcançou nove diferentes posições de bocas usando a mesma boca de troca. $\mathrm{Na}$ animação de substituição essas nove posições, por menor que fosse a variação entre elas, seriam atingidas apenas com nove diferentes bocas.

Figura 14 - Exemplo de boca articula de troca.

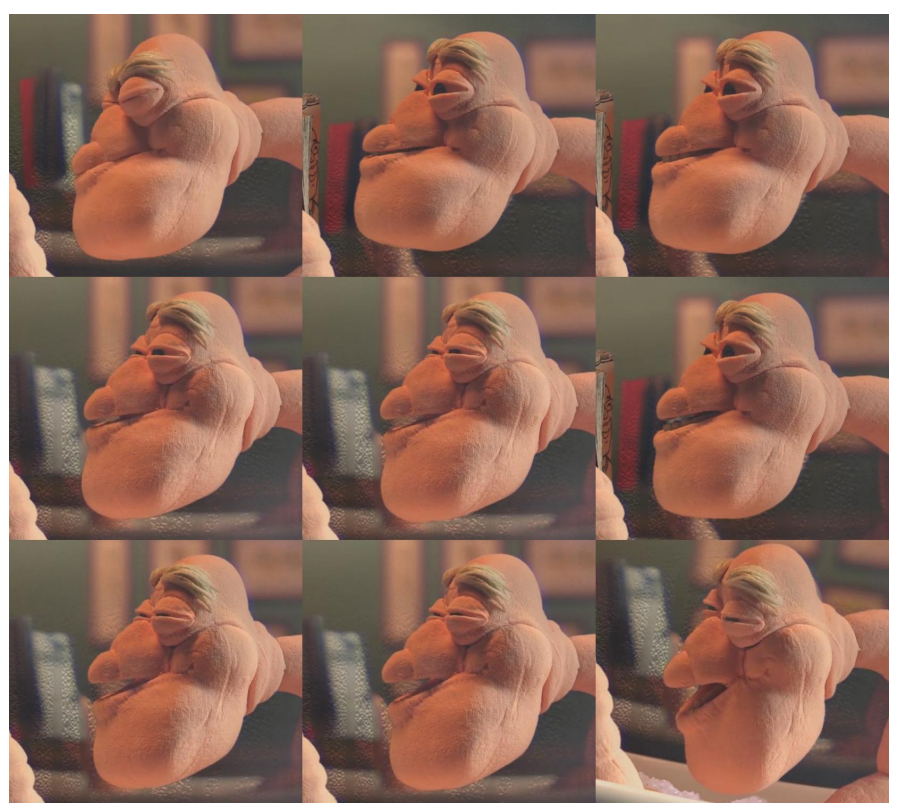

Fonte: Animaking

Como resultado indireto do uso de bocas articuladas de troca o uso do silicone trouxe aos personagens um resultado visual mais realista e sofisticado. A interação do silicone com a luz se assemelha a interação real da luz com a pele humana sendo esse um fator positivo agregado ao novo filme na opinião da produtora.

Figura 15 - Quadro do curta Suspicious Reflection .

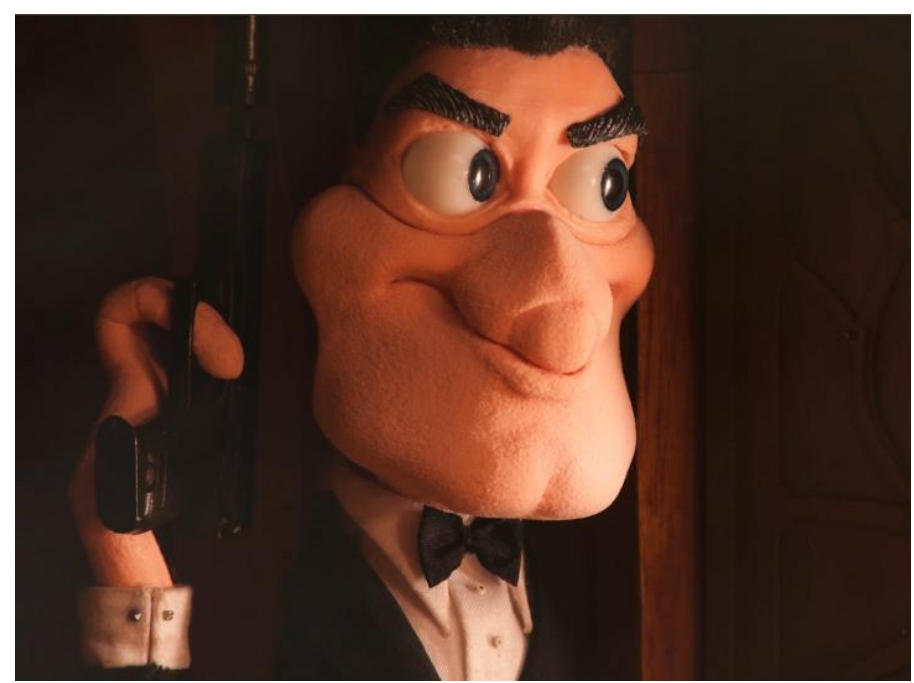


O método demonstrou também otimizar tempo pois todas as estruturas do molde criadas digitalmente podem ser reaproveitadas apenas substituindo as bocas que fazem a subtração do volume, ao passo que em um molde analógico os tempos de construção de diferentes moldes de bocas seriam similares pois não haveria reaproveitamento no processo.

Além disso a transição do processo analógico para o digital modificou o perfil do profissional envolvido no projeto e o gerenciamento de tarefas. Na prática possibilitou a distribuição de tarefas a um maior número de profissionais que podem trabalhar em diferentes etapas de forma paralela e remota ao contrário da forma linear do processo analógico.

Figura 16 - Fluxo de processo de criação de personagem no curta Suspicious Reflection (2018)

\section{Processo Curta Suspicious Reflection (2018)}

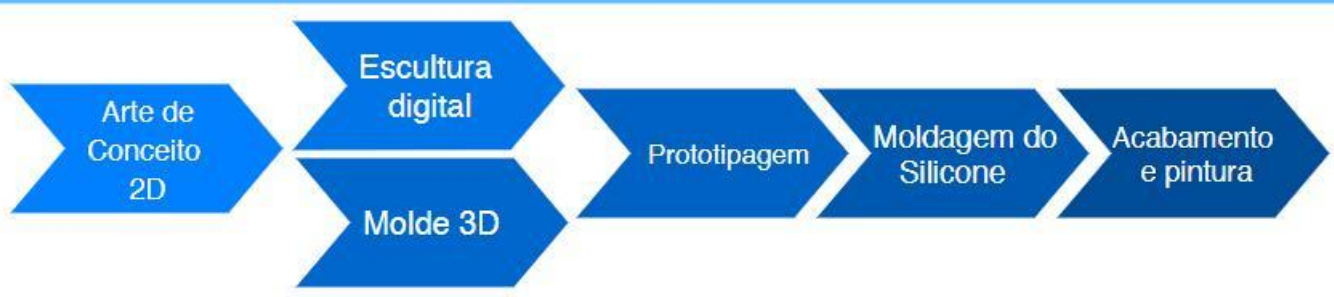

Fonte: o autor

\section{Referências}

ALGER, Jed. The Art and Making Of The ParaNorman. Sam Francisco: Choranicle Books, 2014 AVGERAKIS, George. Digital Animation Bible: Creating Professional Animation with 3ds max, LightWave, and Maya. USA, The McGraw-Hill Companies, 2004.

BUSWELL R.A., Soar R.C., Gibb A.G.F., Thorpe A. Freeform Construction: Megascale Rapid Manufacturing for construction. In: Automation in Construction 16, 2007, p.224-231

MAZZA, Mauricio Duarte. O Acting no design de animação. Dissertação de Mestrado em Design. São Paulo: Universidade Anhembi Morumbi, 2009.

MOLINERO, B. 'Minhocas', primeiro longa em stop-motion do Brasil, foi feito com $\mathbf{6 0 0}$ mil fotos Disponível em: http://www1.folha.uol.com.br/folhinha/2013/12/1388086-primeiro-longabrasileiro-em-stop-motion-minhocas-foi-feito-com-600-mil-fotos.shtml Acesso em: abril de 2018.

PRIEBE, Ken. A. The Advanced Art of Stop-Motion Animation. Vancouver: Delmar Cengage Learning, 2010.

PURVES, Berry J C. Stop Motion: Passion, Progress and Performance. Oxford: Focal Press, 2008.

RASTRO, Agência. Minhocas: elas estão de volta ao nosso festival. Anima Mundi. 2014. Disponível em: http://www.animamundi.com.br/pt/blog/minhocas-elas-estao-de-volta-ao-nossofestival/ Último acesso em 11 de março de 2018. 
VOLPATO, N. Prototipagem Rápida: Tecnologias e Aplicações. São Paulo: Edgard Blucher, 2007. SHAW, Susannah. Stop Motion: Técnicas Manuais Para Animação Com Modelos. Rio de Janeiro: Elsevier, Tradução da 2a Edição. 2012. 